\title{
Evaluation of stability and adapbility of heat-tolerant rice lines in Mekong delta
}

\author{
Lot V. Tran ${ }^{1 *}$, Lang T. Nguyen ${ }^{2}$, Phuoc T. Nguyen ${ }^{2}$, \& Buu C. Bui ${ }^{3}$ \\ ${ }^{1}$ Faculty of Agronomy, Nong Lam University, Ho Chi Minh City, Vietnam \\ ${ }^{2}$ Cuu Long Delta Rice Research Institute, Can Tho, Vietnam \\ ${ }^{3}$ Institute of Agricultural Science for Southern Vietnam, Ho Chi Minh City, Vietnam
}

\begin{abstract}
In two crop seasons of 2018, Winter-Spring and Summer-Autumn, in Long An, Can Tho, Hau Giang, An Giang and Tra Vinh provinces, an assessment of stability and adapability of heat-tolerant rice lines (HTL) was conducted. The experiment was performed as a randomized complete block design (RCBD) with 3 replicates. The quantity of fertilizers was equally applied for all treatments, including $100 \mathrm{~kg} \mathrm{~N}, 40 \mathrm{P}_{2} \mathrm{O}_{5}$ and 30 $\mathrm{kg} \mathrm{K}_{2} \mathrm{O} /$ ha. The results showed that HTL1, HTL2, HTL5, HTL7, and HTL8 were promising hybrid lines as they had short growth periods and high yields with good heat-tolerance. These rice lines were adapted well to both Winter-Spring and Summer-Autumn crops as indicated by the analysis of rice line and environment interaction.
\end{abstract}

Heat-tolerant rice lines Stability

\section{${ }^{*}$ Corresponding author}

Tran Van Lot

Email: tvlot@hcmuaf.edu.vn

Cited as: Tran, L. V., Nguyen, L. T., Nguyen, P. T., \& Bui, B. C. (2019). Evaluation of stability and adapbility of heat-tolerant rice lines in Mekong delta. The Journal of Agriculture and Development 18(4), 1-9. 


\title{
Đánh giá tính ổn định và thích nghi của các dòng lúa chịu nóng tại một số tỉnh Đồng bằng sông Cửu Long
}

\author{
Trần Văn Lợt ${ }^{1 *}$, Nguyễn Thị Lang ${ }^{2}$, Nguyễn Trọng Phước $^{2} \&$ Bùi Chí Bửu ${ }^{3}$ \\ ${ }^{1}$ Khoa Nông Học, Trường Đại Học Nông Lâm TP.HCM, TP. Hồ Chí Minh \\ ${ }^{2}$ Viện Lúa Đồng Bằng Sông Cửu Long, Cần Thơ \\ ${ }^{3}$ Viện Khoa Học Kỹ Thuật Nông Nghiệp Miền Nam, TP. Hồ Chí Minh
}

\section{THÔNG TIN BÀI BÁO \\ Bài báo khoa học \\ Ngày nhận: 15/01/2019 \\ Ngày chỉnh sửa: 01/03/2019 \\ Ngày chấp nhận: 22/03/2019 \\ Từ khóa \\ Dòng lúa chịu nóng \\ Tính ổn định \\ Tính thích nghi \\ *Tác giả liên hệ \\ Trần Văn Lợt \\ Email: tvlot@hcmuaf.edu.vn}

\section{TÓM TẮT}

Cùng với yếu tố năng suất cao và đặc tính nông học tốt, một giống mới được chọn phải có tính ổn định và có tính thích nghi cao trong các điều kiện môi trường khác nhau để gia tăng độ tin cậy về các đặc tính tốt của giống. Bởi vì, khi được trồng tại nhiều địa điểm khác nhau, một số tính trạng về nông học và năng suất có thể sẽ thay đổi do sự tương tác giữa gen và môi trường. Trong hai vụ trồng Đông - Xuân 2017 - 2018 và vụ Hè - Thu 2018 tại các tỉnh Long An, Cần Thơ, Hậu Giang, An Giang và Trà Vinh đã tiến hành đánh giá tính thích nghi và ổn định của các dòng lúa chịu nóng. Các thí nghiệm được bố trí theo khối đầy đủ ngẫu nhiên $(\mathrm{RCBD})$ với ba lần lặp lại. Nền phân bón được áp dụng là $100 \mathrm{~kg}$ $\mathrm{N}, 40 \mathrm{~kg} \mathrm{P}_{2} \mathrm{O}_{5}$ và $30 \mathrm{~kg} \mathrm{~K} 2 \mathrm{O} /$ ha. Kết quả đã xác định có 5 dòng đẳng gen (NIL) triển vọng, ngắn ngày, năng suất cao, chịu nóng là HTL1, HTL2, HTL5, HTL7 và HTL8. Các dòng đẳng gen này thích nghi cả hai vụ Đông - Xuân và Hè - Thu thông qua kết quả phân tích tương tác giữa giống với môi trường.

\section{1. Đặt Vấn Đề}

Việt Nam là một trong số những nước nhiệt đới có khí hậu nóng quanh năm. Trong mùa hè, có những ngày nhiệt độ lên $37^{0} \mathrm{C}-40^{\circ} \mathrm{C}(\mathrm{MARD}$, 2013), đây là ngưỡng gây hại cho cây lúa trong giai đoạn thụ phấn, thụ tinh. Do đó, việc nghiên cứu lai tạo và phát triển những dòng lúa có khả năng chống chịu sốc sinh lý (stress) do nhiệt độ cao là vô cùng bức thiết cho sản xuất lúa gạo tại miền Nam Việt Nam. Trong những năm gần đây, các nhà khoa học về chọn giống đã lai tạo ra nhiều dòng lúa chịu nóng thích ứng với điều kiện biến đổi khí hậu.

Trong chọn tạo giống cây trồng nói chung và đối với cây lúa nói riêng, chọn lọc và đánh giá giống là những công đoạn quan trọng nhất. Cùng với yếu tố năng suất cao và đặc tính nông học tốt, giống được chọn phải có tính ổn định và có tính thích nghi cao trong các điều kiện môi trường khác nhau để gia tăng độ tin cậy về các đặc tính tốt của giống. Bởi vì, khi được trồng tại nhiều địa điểm khác nhau, một số tính trạng về nông học và năng suất có thể sẽ thay đổi do sự tương tác giữa gen và môi trường. Tính ổn định thông thường bao hàm sự thống nhất trong biểu hiện tính trạng, có nghĩa là sự thay đổi tối thiểu giữa các môi trường đối với một kiểu gen cụ thể nào đó (Chahal \& Gosal, 2002). Có những tính trạng do yếu tố di truyền bên trong chi phối; có những tính trạng do cả hai yếu tố di truyền và ngoại cảnh cùng chi phối với nhau hoặc có những tính trạng bị chi phối bởi ngoại cảnh (Bui \& Nguyen, 2003; Bui, 2004). Điều này gây ra khó khăn trong việc chứng minh tính ưu việt của một giống nào đó.

Từ năm 2013, các nhà chọn giống tại Viện Lúa Đồng bằng sông Cửu Long kết hợp với các chuyên gia Hàn Quốc đã lai tạo ra các dòng lúa chịu nóng bằng phương pháp lai hồi giao của các tổ hợp lai giữa giống lúa chịu nóng N22 và Dular với giống lúa AS996, là giống ngắn ngày năng suất 
cao nhưng mẫn cảm với nhiệt độ nóng. Bài báo này trình bày kết quả nghiên cứu phân tích tính ổn định và thích nghi trên tính trạng năng suất của các dòng lúa ngắn ngày chịu nóng triển vọng nhằm mục tiêu chọn lọc giống phù hợp cho từng vùng sinh thái khác nhau của Đồng bằng sông Cửu Long.

\section{Vật Liệu và Phương Pháp Nghiên Cứu}

\subsection{Vật liệu}

Vật liệu nghiên cứu bao gồm 8 dòng lúa chịu nóng triển vọng được chọn lọc từ hai tổ hợp lai hồi giao (AS996/N22; AS996/Dular) và giống N22 là giống đối chứng chịu nóng (nhập nội từ Viện Lúa quốc tế - IRRI) (Bảng 1).

\subsection{Phương pháp nghiên cưuu}

Thí nghiệm thực hiện trong hai vụ: Đông Xuân 2017 - 2018 và vụ Hè - Thu 2018. Địa điểm thí nghiệm gồm: Hậu Giang, An Giang, Long An, Cần Thơ và Trà Vinh. Các thí nghiệm được thực hiện trên ruộng của nông dân, bố trí theo kiểu khối đầy đủ ngẫu nhiên, 3 lần lặp lại. Thí nghiệm được thực hiện bằng phương pháp cấy $(15 \times 20$ cm, 1 tép/bựi), phân bón $100 \mathrm{~kg} \mathrm{~N}, 40 \mathrm{~kg} \mathrm{P}_{2} \mathrm{O}_{5}$ và $30 \mathrm{~kg} \mathrm{~K} \mathrm{~K}_{2} \mathrm{O} / \mathrm{h}$. Mẫu năng suất được thu hoạch là $10 \mathrm{~m}^{2}$. Năng suất được qui về $14 \%$ ẩm độ, sau đó qui ra đơn vị tấn/ha (IRRI, 2012).

Số liệu phân tích từng điểm, qua nhiều điểm bằng phương pháp phân tích phương sai (ANOVA) bằng phầm mềm SAS 9.1, trắc nghiệm phân hạng theo kiểu Duncan. Dựa vào kết quả đánh giá khả năng cho năng suất của các dòng/giống lúa qua các địa điểm khác nhau để phân tích, đánh giá tính ổn định, tính thích nghi của các dòng/giống lúa bằng phần mềm phân tích tính ổn định và tính thích nghi của giống Version 3.0 của Nguyen \& Le (2007) và các công thức tính toán theo mô hình của Eberhart \& Russel (1966).

$$
\mathrm{Y}_{\mathrm{ij}}=\mu_{\mathrm{i}}+\mathrm{b}_{\mathrm{i}} \mathrm{I}_{\mathrm{j}}+\delta_{\mathrm{ij}}
$$

$\mathrm{Y}_{\mathrm{ij}}$ : Năng suất biểu hiện kiểu gen thứ i ( $\left.\mathrm{i}^{\text {th }}\right)$ ở môi trường thứ $\mathrm{j}\left(\mathrm{j}^{\mathrm{th}}\right)$.

$\mu$ : Năng suất trung bình của tất cả các kiểu gen trên tất cả môi trường.

$\mathrm{b}_{i}$ : Hệ số hồi qui của kiểu gen ith theo chỉ số môi trường. $\mathrm{j}^{\text {th }}$.

$\delta_{\mathrm{ij}}$ : Độ lệch từ hồi quy kiểu gen $\mathrm{i}^{\text {th }}$ ở môi trường
$\mathrm{I}_{\mathrm{j}}$ : Chỉ số môi trường và tính bằng công thức $\mathrm{I}_{\mathrm{j}}$ $=\Sigma \mathrm{Y}_{\mathrm{ij}} / \mathrm{G}-\Sigma \Sigma \mathrm{Y}_{\mathrm{ij}} / \mathrm{GL}$.

Hệ số hồi qui bi đo lường phản ứng của kiểu gen theo sự thay đổi môi trường. Sự thích nghi, ổn định của từng kiểu gen qua các môi trường được mô phỏng bằng phương trình hồi qui: $\mathrm{Y}_{\mathrm{ij}}=$ $\mathrm{x}_{\mathrm{i}}+\mathrm{b}_{\mathrm{i}} \mathrm{I}_{\mathrm{j}}$.

Từ đó, năng suất của các giống có thể dự đoán theo phương trình hồi quy: $\mathrm{Y}=\mathrm{X}_{\mathrm{i}}+\mathrm{b}_{\mathrm{i}} \mathrm{I}_{\mathrm{j}}+\mathrm{S}_{\mathrm{di}}^{2}$.

$\mathrm{X}_{\mathrm{i}}$ : năng suất trung bình của giống qua các môi trường.

Hệ số hồi quy $b_{i}$ được tính theo công thức:

$\mathrm{b}_{\mathrm{i}}=\Sigma\left(\mathrm{Y}_{\mathrm{ij}} \mathrm{I}_{\mathrm{j}}\right)$ với $\mathrm{I}_{\mathrm{j}}=\Sigma \mathrm{Y}_{\mathrm{ij}} / \mathrm{G}-\Sigma \Sigma \mathrm{Y}_{\mathrm{ij}} / \mathrm{GL}(\mathrm{G}$ - Số giống, L - Số điểm thí nghiệm).

Chỉ số ổn định được xác định theo công thức:

$$
\begin{aligned}
& \mathrm{S}_{\mathrm{di}}^{2}=\frac{\Sigma \delta_{\mathrm{ij}}^{2}}{\mathrm{~L}-2}-\mathrm{S}_{\mathrm{e}}^{2} \\
& \text { với } \Sigma \delta_{\mathrm{ij}}^{2}=\Sigma \mathrm{Y}_{\mathrm{ij}}^{2}-\frac{\mathrm{Y}_{\mathrm{i}}^{2}}{\mathrm{~L}}-\frac{\left(\Sigma \mathrm{Y}_{\mathrm{ij}} \mathrm{I}_{\mathrm{j}}^{2}\right)^{2}}{\Sigma \mathrm{I}_{\mathrm{j}}^{2}}
\end{aligned}
$$

$\mathrm{s}_{\mathrm{e}}^{2}$ : Trung bình phương sai của kiểu gen trên tất cả môi trường.

r: số lần lặp lại của một kiểu gen trên một môi trường.

Chỉ số thích nghi (bi) của giống:

Nếu $b_{i}=1$ biểu thị tính thích nghi rộng của giống.

Nếu $b_{i}<1$ biểu thị giống thích nghi theo điều kiện môi trường bất lợi.

Nếu $b_{i}>1$ biểu thị tính thích nghi của giống theo điều kiện môi trường thuận lợi.

Chỉ số ổn định $\mathrm{S}_{\mathrm{di}}^{2}$ của giống có xu hướng tiến đến 0 nếu:

$\mathrm{S}_{\mathrm{di}}^{2}=0$ được xem là ổn định; $\mathrm{S}_{\mathrm{di}}^{2} \neq 0$ thì không ổn định.

$\mathrm{S}_{\mathrm{di}}^{2}>0$ có ý nghĩa, giống sẽ có năng suất không ổn định. Không chấp nhận giả thuyết về tương tác gen và môi trường $(\mathrm{GxE})$ tuyến tính.

Phân tích theo mô hình tương tác đa phương AMMI:

Mô hình tương tác đa phương AMMI do Ramagora và Fox (1993) đề xuất, được trích dẫn bởi Bui \& Nguyen, 2003.

Mô hình tổng quát: $\mathrm{Y}_{\mathrm{ij}}=\mu+\mathrm{g}_{\mathrm{i}}+\mathrm{e}_{\mathrm{j}}+\mathrm{d}_{\mathrm{ij}}$

Trong đó:

$Y_{\mathrm{ij}}$ : Năng suất của giống thứ $\mathrm{i}^{\text {th }}$ ở môi trường thứ $\mathrm{j}^{\text {th }}$.

$\mu$ : Năng suất trung bình trên tất cả các điểm. 
Bảng 1. Chiều cao cột khí $\mathrm{CO}_{2}(\mathrm{~cm})$ trong ống Durham

\begin{tabular}{cccl}
\hline $\begin{array}{c}\text { Tên } \\
\text { giống }\end{array}$ & Dòng lai & $\begin{array}{c}\text { Tổ hợp lai hồi } \\
\text { giao }\end{array}$ & Đặc điểm \\
\hline HTL1 & BC3-2-2-3-1 & AS996*4/N22 & Chịu nóng, ngắn ngày, năng suất cao, phẩm chất tốt \\
HTL2 & BC3F2-1-9 & AS996*4/N22 & Ngắn ngày, năng suất cao, phẩm chất tốt, chịu nóng \\
HTL3 & BC3-1-5 & AS996*4 Dular & Ngắn ngày, năng suất cao, chịu nóng \\
HTL4 & BC3-32 & AS996*4/Dular & Ngắn ngày, năng suất cao, chịu nóng \\
HTL5 & BC3F2-32 & AS996*4/N22 & Ngắn ngày, năng suất cao, chịu nóng \\
HTL6 & BC3F2-34 & AS996*4/N22 & Ngắn ngày, năng suất cao, chịu nóng \\
HTL7 & BC3F2-35 & AS996*4/N22 & Ngắn ngày, năng suất cao, chịu nóng \\
HTL8 & BC3F2-40 & AS996*4/N22 & Ngắn ngày, năng suất cao, chịu nóng, phẩm chất tốt \\
N22 & & Từ Hàn Quốc & Ngắn ngày, chịu nóng \\
(IRRI) & \\
\hline
\end{tabular}

${ }^{1}$ HTL: Heat-tolerant line.

$\mathrm{g}_{\mathrm{i}}$ : Độ lệnh chuẩn với giá trị trung bình của giống i.

$\mathrm{e}_{\mathrm{j}}$ : Độ lệnh chuẩn với giá trị trung bình của môi trường $\mathrm{j}$.

$\mathrm{d}_{\mathrm{ij}}$ : Độ lệch chuẩn cặn chưa được giải thích bởi $\mu, g_{i}$ và $e_{j}$.

Mô hình AMMI được phân tích trên phần mềm IRRISTAT 5.0 theo phương pháp thông dụng là xếp nhóm, phân tích thành phần chính đóng góp vào tính trạng theo dõi, xác định quan hệ giữa các kiểu gen thí nghiệm và giữa các môi trường canh tác.

\section{Kết Quả và Thảo Luận}

3.1. Đánh giá tính ổn định, thích nghi về năng suất và tương tác giữa kiểu gen và mồi trường của các dòng lúa chịu nóng triển vọng trồng vụ Đông - Xuân 2017 - 2018

3.1.1. Phân tích năng suất qua nhiều điểm của các dòng lúa chịu nóng triển vọng trồng vụ Đông - Xuân 2017 - 2018

Phân tích qua nhiều điểm có thể giải thích tầm quan trọng sự biến đổi của giống, địa điểm và sự tương tác giữa giống và địa điểm. Tuy nhiên, sự phân tích này không thể xác định những giống nào ổn định hơn. Khi các giống được thử nghiệm qua nhiều điểm thì sự xếp hạng của các giống này có thể thay đổi từ địa điểm này đến địa điểm khác. Vì thế, nó trở nên khó để khuyến cáo giống nào là ưu việt (Nguyen \& Le, 2007).

Kết quả Bảng 2 cho thấy năng suất của các các dòng lai ở các địa điểm khác biệt không có ý nghĩa thống kê $(P>0,05)$ ngoại trừ điểm thí nghiệm tại Trà Vinh, trong đó đa số các dòng đẳng gen cho năng suất cao khác biệt với dòng đẳng gen HTL3.

Phân tích phương sai (ANOVA) qua nhiều điểm cho thấy năng suất giữa các địa điểm khác biệt không có ý nghĩa thống kê $(P>0,05)$ và năng suất trung bình của các địa điểm giữa các dòng đẳng gen có sự khác biệt rất có ý nghĩa $(P$ $<0,01)$. Dòng đẳng gen HTL5 cho năng suất cao nhất (7,38 tấn/ha), khác biệt không có ý nghĩa thống kê với các dòng đẳng gen HTL7, HTL8, HTL1, HTL2 nhưng khác biệt với các dòng đẳng gen còn lại và giống đối chứng N22.

Số liệu Bảng 2 cũng cho thấy chỉ số môi trường $\left(\mathrm{I}_{\mathrm{j}}\right)$ theo thứ tự từ môi trường thuận lợi đến kém thuận lợi: Cần Thơ = An Giang > Trà Vinh > Long An > Hậu Giang theo thứ tự: 0,133; 0,133; 0,$052 ; 0,037 ;-0,356$.

\subsubsection{Phân tích ổn định, thích nghi các dòng lúa chịu nóng triển vọng về năng suất trồng vụ Đông - Xuân 2017 - 2018}

Kết quả phân tích ANOVA cho phép xem xét mối tương tác giữa giống và môi trường ở đây là tuyến tính. Phân tích chỉ số ổn định và chỉ số thích nghi của các giống được đánh giá là quan trọng trong việc đánh giá một giống tốt. Giống ổn định về năng suất là giống có năng suất trung bình cao qua các địa điểm, có chỉ số ổn định $\left(\mathrm{S}_{\mathrm{di}}^{2}\right.$ $\approx 0$ ) và thích nghi rộng $\left(\mathrm{b}_{\mathrm{i}} \approx 1\right)$. Nếu $\mathrm{b}_{\mathrm{i}}<1$, biểu thị tính thích nghi theo điều kiện bất lợi. Nếu $b_{i}$ $>1$, biểu thị tính thích nghi theo điều kiện thuận lợi của môi trường. Nếu $\mathrm{S}_{\mathrm{di}}^{2} \neq 0$ : giống không ổn định năng suất (Bui, 2003; Nguyen \& Le, 2007; Nguyen \& ctv., 2016).

Số liệu ở Bảng 3 cho thấy ba dòng đẳng gen HTL5, HTL7 và HTL8 cho năng suất trung bình 
Bảng 2. Năng suất (tấn/ha) của bộ giống lúa khảo nghiệm tại 5 điểm vụ Đông - Xuân 2017 2018

\begin{tabular}{ccccccc}
\hline Tên giống $^{1}$ & Cần Thơ & Long An & An Giang & Trà Vinh & Hậu Giang & Trung bình \\
\hline HTL1 & 7,46 & 7,20 & 7,23 & $7,37 \mathrm{a}$ & 6,32 & $7,12^{\mathrm{ab}}$ \\
HTL2 & 7,53 & 7,16 & 7,16 & $7,47^{\mathrm{ab}}$ & 6,06 & $7,08^{\mathrm{ab}}$ \\
HTL3 & 7,03 & 6,60 & 6,76 & $6,17^{\mathrm{c}}$ & 6,53 & $6,64^{\mathrm{b}}$ \\
HTL4 & 6,73 & 6,66 & 6,83 & $7,27 \mathrm{ab}$ & 6,73 & $6,85^{\mathrm{ab}}$ \\
HTL5 & 7,46 & 7,60 & 7,73 & $7,37^{\mathrm{ab}}$ & 6,73 & $7,38^{\mathrm{a}}$ \\
HTL6 & 6,86 & 7,10 & 6,76 & $7,03^{\mathrm{ab}}$ & 6,86 & $6,93^{\mathrm{ab}}$ \\
HTL7 & 7,16 & 6,93 & 7,63 & $7,33^{\mathrm{ab}}$ & 7,06 & $7,23^{\mathrm{a}}$ \\
HTL8 & 7,26 & 7,40 & 7,50 & $7,30^{\mathrm{bc}}$ & 6,96 & $7,29^{\mathrm{a}}$ \\
N22 & 7,03 & 6,93 & 6,93 & $6,53^{\mathrm{bc}}$ & 6,86 & $6,86^{\mathrm{ab}}$ \\
\hline Trung bình & 7,17 & 7,08 & 7,17 & 7,09 & 6,68 & 7,04 \\
CV (\%) & 4,68 & 7,07 & 7,15 & 6,51 & 6,61 & 6,46 \\
Prob. & $>0,05$ & $>0,05$ & $>0,05$ & $<0,05$ & $>0,05$ & $<0,01$ \\
\hline Chỉ số $\mathrm{I}_{\mathrm{j}}$ & 0,133 & 0,037 & 0,133 & 0,052 & $-0,356$ &
\end{tabular}

${ }^{1}$ HTL: Heat-tolerant line.

a-c Trong cùng một cột, các số có cùng chữ cái giống nhau thì khác biệt không có ý nghĩa thống kê ở mức $P$ < 0,05 và 0,01 theo trắc nghiệm Duncan.

Bảng 3. Năng suất trung bình (tấn/ha), chỉ số ổn định và chỉ số thích nghi của các dòng lúa trồng vụ Đông - Xuân 2017 - 2018

\begin{tabular}{|c|c|c|c|c|}
\hline Tên giống ${ }^{1}$ & $\begin{array}{l}\text { Năng suất trung } \\
\text { bình giống nhau, } \\
\text { dùng để nhận xét } \\
\text { chỉ số } \mathrm{S}_{\mathrm{di}}^{2} \text { và } \mathrm{b}_{\mathrm{i}}\end{array}$ & $\begin{array}{l}\text { Chỉ số ổn định } \\
\left(\mathrm{S}_{\mathrm{di}}^{2}\right)\end{array}$ & $\begin{array}{l}\text { Chỉ số thích nghi } \\
\qquad\left(\mathrm{b}_{\mathrm{i}}\right)\end{array}$ & $\begin{array}{c}\text { Sai số chuẩn } \\
\text { của chỉ số thích } \\
\text { nghi }\left(b_{\mathrm{i}}\right)\end{array}$ \\
\hline HTL1 & $7,12^{\mathrm{abc}}$ & $-0,051$ & $2,149^{*}$ & 0,324 \\
\hline HTL2 & $7,08^{\mathrm{abc}}$ & $-0,020$ & $2,744^{*}$ & 0,543 \\
\hline HTL3 & $6,64^{\mathrm{c}}$ & 0,053 & 0,512 & 0,858 \\
\hline HTL4 & $6,85^{\mathrm{bc}}$ & 0,006 & 0,232 & 0,673 \\
\hline HTL5 & $7,38^{\mathrm{a}}$ & $-0,045$ & 1,783 & 0,378 \\
\hline HTL6 & $6,93^{\mathrm{abc}}$ & $-0,044$ & $0,024^{*}$ & 0,386 \\
\hline HTL7 & $7,23^{\mathrm{ab}}$ & 0,009 & 0,589 & 0,686 \\
\hline HTL8 & $7,29^{\mathrm{ab}}$ & $-0,057$ & 0,870 & 0,268 \\
\hline N22 & $6,86^{\mathrm{bc}}$ & $-0,020$ & 0,098 & 0,541 \\
\hline
\end{tabular}

cao lần lượt là 7,$78 ; 7,23$ và 7,29 tấn/ha, nhưng sự khác biệt này không có ý nghĩa thống kê với nhau; có chỉ số ổn định $\mathrm{S}_{\mathrm{di}}^{2} \approx 0(P>0,05)$; chỉ số thích nghi (bi) từ 0,589 dến $1,783 \approx 1(P>0,05)$. Do đó, các dòng đẳng gen này ổn định về năng suất và thích nghi rộng. Đặc biệt, dựa vào số liệu Bảng 3 cũng cho thấy dòng đẳng gen HTL1 và HTL2 có năng suất trung bình cao, ổn định $\left(\mathrm{S}_{\mathrm{di}}^{2}\right.$ ح 0 ) không khác biệt với HTL5, HTL7 và HTL8 nhưng thích nghi với môi trường thuận lợi $\left(b_{i}>\right.$ $1)$.

\subsubsection{Phân nhóm kiểu gen và môi trường của các dòng lúa chịu nóng triển vọng trồng vụ Đông - Xuân 2017 - 2018}

Giản đồ Biplot (Hình 1) cho thấy sự tương tác kiểu gen với môi trường đạt $82,5 \%$ theo mô hình AMMI 2. Giản đồ cho thấy mỗi dòng đẳng gen có sự tương tác với môi trường khác nhau. Những dòng đẳng gen phân bố gần điểm giao nhau của các đường thẳng thì thích nghi rộng với môi trường đó. Và cũng theo lý thuyết mô hình AMMI 2 (Nguyen, 2002), dòng đẳng gen HTL8 nằm gần trục trung tâm do đó thích nghi rộng 
với tất cả các môi trường.

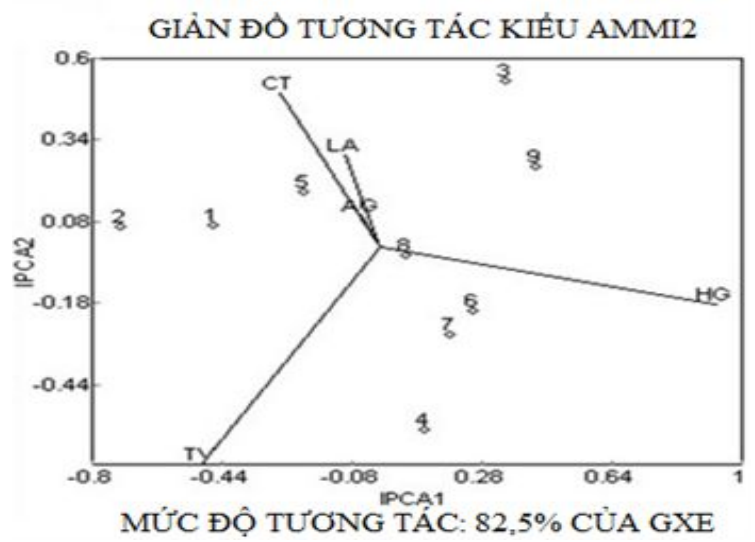

Hình 1. Giản đồ Biplot tương tác kiểu gen và môi trường theo mô hình AMM2.

Dòng lai: 1. HTL1, 2. HTL2, 3. HTL3, 4. HTL4, 5. HTL5, 6. HTL6, 7. HTL7, 8. HTL8, 9. N22 (đ/chứng). HTL: Heat-tolerant line.

Địa điểm: AG: An Giang, CT: Cần Thơ, HG: Hậu Giang, LA: Long An, TV: Trà Vinh.

Giản đồ phân nhóm môi trường theo mô hình AMMI của các dòng lúa trồng vụ Đông - Xuân 2017 - 2018 được tình bày ở Hình 2(A). Giữa các nhóm môi trường có sự khác biệt khá lớn với mức độ dung hợp (Fushion level) từ 0,42 đến 2,90; dựa vào mức độ dung hợp 1,04 chia các địa điểm trồng thành 2 nhóm: Nhóm 1 gồm Cần Thơ, Long An, An Giang và Trà Vinh; năng suất trung bình cao từ 7,08 đến 7,17 tấn/ha; Nhóm 2: Hậu Giang; năng suất thấp 6,68 tấn/ha.

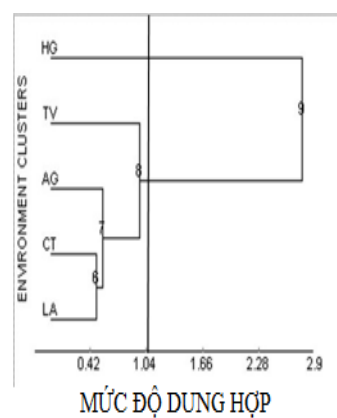

(A)

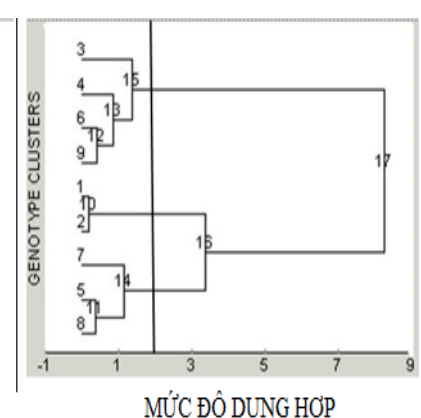

(B)
Hình 2. Phân nhóm môi trường $(\mathrm{A})$ và kiểu gen $(\mathrm{B})$ của các dòng lai qua 5 môi trường vụ Đông - Xuân 2017 - 2018. AG: An Giang, CT: Cần Thơ, HG: Hậu Giang, LA: Long An, TV: Trà Vinh.

Giản đồ phân nhóm kiểu gen của các dòng lúa thí nghiệm trong vụ Đông - Xuân năm 2017 -
2018 được thể hiện qua Hình 2(B). Qua giản đồ này thì các kiểu gen giống nhau thì xếp cùng nhóm và ở mức dung hợp 1,98 và với hệ số xác định $\left(\mathrm{R}^{2}=0,727\right)$ so sánh UPGMA hệ số Euclid bằng phần mềm SAS 9.1 chia các dòng đẳng gen thành 3 nhóm: Nhóm 1 có ba dòng đẳng gen HTL3, HTL4, HTL6 và giống đối chứng N22; trong nhóm này các dòng đẳng gen đạt năng suất thấp theo thứ tự là 6,64 tấn $/$ ha; 6,$85 ; 6,93$ và 6,86 tấn/ha; Nhóm 2: Hai dòng đẳng gen HTL1 và HTL2 với biểu hiện năng suất tương đối cao theo thứ tự là 7,12 tấn/ha và 7,08 tấn/ha; Nhóm 3: Ba dòng đẳng gen HTL7, HTL8 và HTL5; các dòng đẳng gen này cho năng suất rất cao theo thứ tự là 7,$23 ; 7,28$ và 7,38 tấn/ha.

3.2. Đánh giá tính ổn định, thích nghi về năng suất và tương tác giữa kiểu gen và mồi trường của các dòng lúa chịu nóng triển vọng trồng vụ Hè - Thu năm 2018

\subsubsection{Phân tích qua nhiều điểm các dòng lúa chịu} nóng triển vọng trồng vụ Hè - Thu năm 2018

Kết quả ở Bảng 4 cho thấy phân tích phương sai (ANOVA) qua nhiều điểm năng suất ở các địa điểm khác biệt không có ý nghĩa thống kê $(P>$ $0,05)$ và năng suất trung bình của các địa điểm thí nghiệm giữa các dòng lai có sự khác biệt rất có ý nghĩa $(P<0,01)$. Có bốn dòng đẳng gen cho năng suất tương đương nhau khác biệt có ý nghĩa thống kê so với giống đối chứng N22. Trong đó, dòng đẳng gen HTL7 đạt năng suất cao nhất 5,97 tấn/ha, dòng đẳng gen HTL8 đạt 5,84 tấn/ha. Hai dòng đẳng gen này cũng cho năng suất cao nhất ở vụ Đông - Xuân 2017 - 2018.

Số liệu ở Bảng 4 cũng cho thấy chỉ số môi trường $\left(\mathrm{I}_{\mathrm{j}}\right)$ theo thứ tự từ môi trường thuận lợi đến kém thuận lợi: Hậu Giang > Trà Vinh > An Giang > Long An > Cần Thơ theo thứ tự: 0,373; 0,$096 ; 0,062 ;-0,156 ;-0,375$.

3.2.2. Phân tích ổn định, thích nghi các dòng lúa chịu nóng triển vọng về năng suất trồng vụ Hè - Thu 2018

Kết quả trình bày ở Bảng 5 cho thấy ba dòng đẳng gen HTL 6 , HTL7 và HTL8 cho năng suất trung bình cao theo thứ tự: 5,$89 ; 5,97$ và 5,84 tấn/ha, sự khác biệt này không có ý nghĩa thống kê với nhau, có chỉ số ổn định $\mathrm{S}_{\mathrm{di}}^{2} \approx 0(P>0,05)$, chỉ số thích nghi (bi) theo thứ tự: 1,$441 ; 1,62$ và $1,89 \approx 1(P>0,05)$. Do đó, các dòng đẳng gen này ổn định về năng suất và thích nghi rộng. 
Bảng 4. Năng suất (tấn/ha) của bộ giống lúa khảo nghiệm tại 5 địa điểm vụ Hè - Thu 2018

\begin{tabular}{ccccccc}
\hline Tên giống $^{1}$ & Cần Thơ & Long An & An Giang & Trà Vinh & Hậu Giang & Trung bình \\
\hline HTL1 & 5,43 & 5,57 & 5,30 & 5,60 & 6,13 & $5,60^{\text {ab }}$ \\
HTL2 & 5,00 & 5,67 & 5,57 & 5,77 & 5,67 & $5,53^{\mathrm{ab}}$ \\
HTL3 & 5,20 & 5,77 & 5,67 & 5,03 & 6,37 & $5,60^{\mathrm{ab}}$ \\
HTL4 & 5,67 & 5,40 & 5,87 & 5,37 & 5,60 & $5,58^{\mathrm{ab}}$ \\
HTL5 & 5,77 & 5,37 & 5,53 & 6,00 & 6,10 & $5,75^{\mathrm{a}}$ \\
HTL6 & 5,70 & 5,20 & 5,93 & 6,00 & 6,60 & $5,87^{\mathrm{a}}$ \\
HTL7 & 5,37 & 5,40 & 6,08 & 6,70 & 6,30 & $5,97^{\mathrm{a}}$ \\
HTL8 & 4,96 & 5,50 & 6,27 & 6,20 & 6,27 & $5,84^{\mathrm{a}}$ \\
N22 & 4,30 & 5,50 & 5,13 & 4,97 & 5,10 & $5,00^{\mathrm{b}}$ \\
\hline Trung bình & 5,27 & 5,49 & 5,70 & 5,74 & 6,02 & 5,64 \\
CV(\%) & 10,56 & 11,93 & 14,24 & 15,81 & 9,34 & 12,62 \\
Prob. & $>0,05$ & $>0,05$ & $>0,05$ & $>0,05$ & $>0,05$ & $<0,01$ \\
Chỉ số $\left(\mathrm{I}_{\mathrm{j}}\right.$ ) trường $\mathrm{I}_{\mathrm{j}}$ & $-0,375$ & $-0,156$ & 0,062 & 0,096 & 0,373 & \\
\hline
\end{tabular}

${ }^{1}$ HTL: Heat-tolerant line.

a-b Trong cùng một cột, các số có cùng chữ cái giống nhau thì khác biệt không có ý nghĩa thống kê ở mức $P$ < 0,01 theo trắc nghiệm Duncan.

Bảng 5. Năng suất trung bình (tấn/ha), chỉsố ổn định và chỉ số thích nghi của các dòng lúa trồng vụ Hè - Thu năm 2018

\begin{tabular}{ccrcc}
\hline Tên giống ${ }^{1}$ & Năng suất trung bình & $\begin{array}{c}\text { Chỉ số ổn định } \\
\left(\mathrm{S}_{\mathrm{di}}^{2}\right)\end{array}$ & $\begin{array}{c}\text { Chỉ số thích nghi } \\
\left(\mathrm{b}_{\mathrm{i}}\right)\end{array}$ & $\begin{array}{c}\text { Sai số chuẩn } \\
\text { của chỉ số thích } \\
\text { nghi }\left(\mathrm{b}_{\mathrm{i}}\right)\end{array}$ \\
\hline HTL1 & $5,61^{\mathrm{ab}}$ & $-0,099$ & 0,782 & 0,469 \\
HTL2 & $5,53^{\mathrm{ab}}$ & $-0,111$ & 0,798 & 0,427 \\
HTL3 & $5,61^{\mathrm{ab}}$ & 0,062 & 1,135 & 0,853 \\
HTL4 & $5,58^{\mathrm{ab}}$ & $-0,113$ & $0,002^{*}$ & 0,420 \\
HTL5 & $5,75^{\mathrm{ab}}$ & $-0,083$ & 0,614 & 0,522 \\
HTL6 & $5,89^{\mathrm{a}}$ & $-0,045$ & 1,441 & 0,624 \\
HTL7 & $5,97^{\mathrm{a}}$ & $-0,000$ & 1,621 & 0,730 \\
HTL8 & $5,84^{\mathrm{a}}$ & $-0,091$ & 1,893 & 0,497 \\
N22 & $5,00 \mathrm{~b}$ & 0,033 & 0,714 & 0,799 \\
\hline Prob. & $<0,01$ & & \\
\hline
\end{tabular}

${ }^{1}$ HTL: Heat-tolerant line.

${ }^{\mathrm{a}-\mathrm{b}}$ Trong cùng một cột, các số có cùng chữ cái giống nhau thì khác biệt không có ý nghĩa thống kê ở mức $P$ < 0,01 theo trắc nghiệm Duncan; *: có ý nghĩa thống kê ở mức $P<0,05\left(b_{\mathrm{i}} \neq 1\right)$.

3.2.3. Phân nhóm kiểu gen và môi trường của các dòng lúa chịu nóng triển vọng trồng vụ Hè - Thu năm 2018

Giản đồ Biplot (Hình 3) cho thấy sự tương tác kiểu gen với môi trường đạt 74,5\% theo mô hình AMMI2. Giản đồ cho thấy mỗi dòng lúa có sự tương tác với môi trường khác nhau. Dòng đẳng gen HTL7 nằm gần dường thẳng của điểm Trà Vinh nên cho năng suất cao và thích nghi rộng với môi trường này.

Giản đồ phân nhóm môi trường theo mô hình AMMI của các dòng đẳng gen trồng vụ Hè Thu 2018 được tình bày ở Hình 4A. Giữa các nhóm môi trường có sự khác biệt khá lớn với mức độ dung hợp (Fushion level) từ -0,2 đến 3,60; dựa vào mức độ dung hợp 1,2 chia các địa điểm thí nghiệm thành 3 nhóm: Nhóm 1 gồm hai môi trường khảo nghiệm là Cần Thơ và Hậu Giang; tại môi trường Hậu Giang năng suất đạt cao nhất 6,02 tấn/ha; Nhóm 2 gồm một môi trường là Long An; năng suất đạt 5,49 tấn/ ha; Nhóm 3 gồm hai môi trường thí nghiệm An Giang và Trà Vinh. Tại hai môi trường này năng suất các dòng lai đạt tương đương nhau và đạt khá cao. Điểm An Giang đạt 5,7 tấn/ha và điểm Trà Vinh đạt 5,74 tấn/ha.

Giản đồ phân nhóm kiểu gen của các dòng lúa khảo nghiệm trong vụ Hè - Thu năm 2018 được 
GIẢN ĐỔ TƯƠNG TÁC KIÊU AMMI2

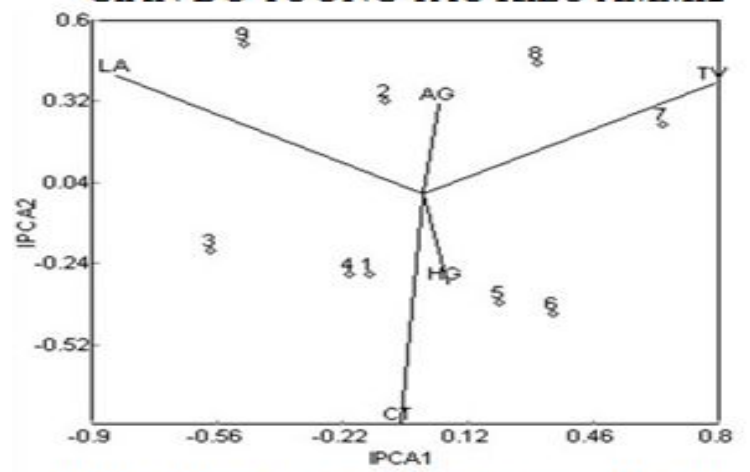

MỨC Độ TƯƠNG TÁC: $74,5 \%$ CỦA GXE

Hình 3. Giản đồ Biplot tương tác kiểu gen và môi trường theo mô hình AMM2.

Dòng lai: 1. HTL1, 2. HTL2, 3. HTL3, 4. HTL4, 5. HTL5, 6. HTL6, 7. HTL7, 8. HTL8, 9. N22 (đ/chứng). HTL: Heat-tolerant line.

Địa điểm: AG: An Giang, CT: Cần Thơ, HG: Hậu Giang, LA: Long An, TV: Trà Vinh.

thể hiện qua Hình 4B. Qua giản đồ này thì các kiểu gen giống nhau thì xếp cùng nhóm và ở mức dung hợp 1,8 và với hệ số xác định $\left(\mathrm{R}^{2}=0,763\right)$ so sánh UPGMA hệ số Euclidean bằng phần mềm SAS 9.1 chia các dòng lúa thành 4 nhóm: Nhóm 1 có duy nhất giống đối chứng N22; đạt năng suất thấp nhất 5,00 tấn/ha; Nhóm 2: Ba dòng đẳng gen HTL1, HTL2 và HTL3 với biểu hiện năng suất tương đối cao theo thứ tự là 5,$61 ; 5,53$ và 5,61 tấn/ha; Nhóm 3: Ba dòng đẳng gen HTL4, HTL5 và HTL6; các dòng lúa này cho năng suất cao theo thứ tự là 5,$58 ; 5,75$ và 5,89 tấn/ha; Nhóm 4: Hai dòng đẳng gen HTL7 và HTL8. Các dòng đẳng gen này cho năng suất rất cao theo thứ tự là 5,97 và 5,84 tấn/ha.

Tóm lại, qua phân tích tích tính ổn định, thích nghi của các dòng lúa chịu nóng triển vọng trong hai vụ Đông - Xuân 2017 - 2018 và vụ Hè - Thu 2018 theo mô hình tuyến tính của Eberhart \& Russell (1966) cho thấy dòng đẳng gen HTL8 cho năng suất cao ổn định, thích nghi rộng qua hai vụ.

\section{Kết Luận và Đề Nghị}

\subsection{Kết luận}

Kết quả thí nghiệm về phân tích tính ổn định về năng suất của tám dòng lúa chịu nóng triển vọng qua hai vụ Đông - Xuân 2017- 2018 và Hè - Thu 2018 qua năm tỉnh Cần Thơ, Long An,

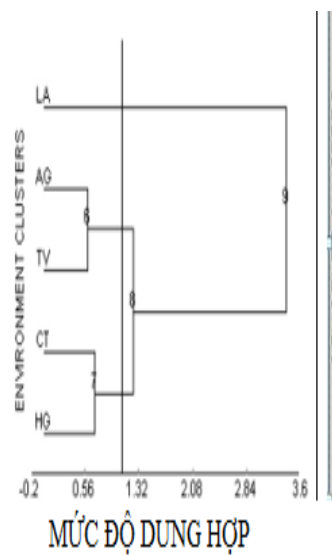

(A)

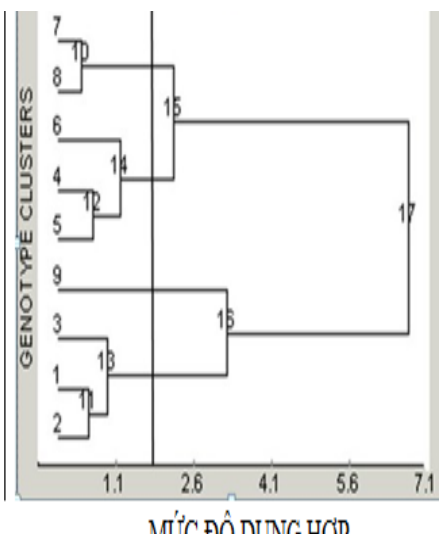

MỨC ĐỘ DUNG HỢP

(B)
Hình 4. Phân nhóm môi trường $(\mathrm{A})$ và kiểu gen $(\mathrm{B})$ của các dòng lai qua 5 môi trường vụ Hè - Thu 2018. AG: An Giang, CT: Cần Thơ, HG: Hậu Giang, LA: Long An, TV: Trà Vinh.

An Giang, Trà Vinh và Hậu Giang đã xác định có 5 dòng lúa triển vọng, ngắn ngày, năng suất cao, chịu nóng được chọn lọc là HTL1, HTL2, HTL5, HTL7 và HTL8. Các dòng lúa này thích nghi cả hai vụ Đông - Xuân và Hè - Thu thông qua kết quả phân tích tương tác giữa giống với môi trường. Trong đó, dòng lúa HTL8 cho năng suất cao ổn định, thích nghi rộng qua hai vụ, đây là dòng lúa có triển vọng có thể đưa vào khảo nghiệm các bước tiếp theo.

\section{2. Đề nghị}

Dòng lúa HTL8 cho năng suất cao, ổn định, thích nghi rộng qua hai vụ, đây là dòng lúa có triển vọng có thể đưa vào khảo nghiệm có hệ thống, nhanh chóng phát triển trong sản xuất.

\section{Tài Liệu Tham Khảo (References)}

Bui, B. C. (2004). Selection of rice varieties by the traditional method of improving rice varieties to meet the requirements of agricultural development till 2010. In National conference on selection of rice varieties. Can Tho, Vietnam: Cuu Long Delta Rice Research Institute.

Bui, B. C., \& Nguyen, L. T. (2003). A textbook of quantitative genetics. Ha Noi, Vietnam: Agricultural Publishing House.

Chahal, G. S., \& Gosal, S. S. (2002). Genetic transformation and production of transgenic plants. In Principles and Procedures of Plant Breeding - Bitechnical and Convention Approaches (486-508). Pangbourne, UK: Narosa Publishing House. 
Eberhart, S. A., \& Russel, W. L. (1966). Stability parameters for comparing varieties. Crop Science 6(1), $36-40$.

IRRI (International Rice Research Institute). (2013). Standard evaluation system for rice ( $5^{\text {th }}$ ed.). Manila, Philippines: IRRI.

MARD (Ministry of Agriculture and Rural Development). (2013). Summation meeting of rice production in 2012 and plan for the year 2013 in South Vietnam. Ha Noi, Vietnam: Agricultural Publishing House.

Nguyen, H. D., \& Le, K. Q. (2007). Analysis stability index in plant beeeding. Vietnam Journal of Agricultural Sciences 5(1), 67-72.
Nguyen, L. T. (2002). Statistical lectures: gene and environment interaction. Cuu Long Delta Rice Research Institute, Can Tho, Vietnam.

Nguyen, L. T., Pham, T. C., Nguyen, H. N., Tran, X. T. T., \& Bui, B. C. (2016). Evaluation of genotype and environment interaction of salt-tolerant rice varieties in Mekong delta. Vietnam Journal of Science, Technology and Engineering 68, 40-44. 